\title{
Temperament among offspring at high and low risk for depression
}

\author{
Beth Bruder-Costello $^{\mathrm{a}, \mathrm{b}}$, Virginia Warner ${ }^{\mathrm{a}, \mathrm{b}}$, Ardesheer Talati ${ }^{\mathrm{a}, \mathrm{b}}$, Yoko Nomura ${ }^{\mathrm{a}}$, \\ Gerard Bruder $^{\mathrm{a}, \mathrm{c}}$, Myrna Weissman ${ }^{\mathrm{a}, \mathrm{b}, *}$ \\ ${ }^{a}$ Department of Psychiatry, College of Physicians and Surgeons, Columbia University, New York, NY 10032, USA \\ ${ }^{\mathrm{b}}$ Division of Clinical and Genetic Epidemiology New York State Psychiatric Institute, New York, NY 10032, USA \\ ${ }^{\mathrm{c}}$ Division of Biopsychology, New York State Psychiatric Institute, New York, NY 10032, USA
}

Received 28 February 2006; received in revised form 15 November 2006; accepted 14 February 2007

\begin{abstract}
The purpose of this study was to examine relationships between parental depression, offspring temperament, and offspring major depressive disorder (MDD), and to determine whether difficult temperament, as measured by the Dimensions of Temperament Survey (DOTS), mediates the relation between parental MDD and offspring MDD. Offspring $(n=169)$ of depressed or never depressed parents were followed over approximately 20 years and were blindly assessed up to 4 times (Waves 1 to 4 ) using semi-structured interviews. Offspring completed the DOTS at the time of first or second assessment. The results showed: (1) high-risk offspring with one or more depressed parent were significantly more likely than offspring with neither parent depressed to have a difficult temperament; (2) offspring with a difficult temperament were more than twice as likely as those with an easy temperament to develop a MDD; and (3) difficult temperament explained more than $10 \%$ of the association between parental depression and new onsets of MDD in offspring. The findings suggest that offspring temperament is associated with development of MDD and that difficult temperament at least partially mediates the relationship between parental depression and offspring depression. When identifying those at greatest risk for MDD, measures of temperament could serve as a useful supplement to family psychiatric history of MDD.
\end{abstract}

(C) 2007 Elsevier Ireland Ltd. All rights reserved.

Keywords: Dimensions of Temperament Survey (DOTS); Major depressive disorder (MDD)

\section{Introduction}

Numerous longitudinal and family history studies have demonstrated that the offspring of parents with Major Depressive Disorder (MDD) are at a two- to threefold increased risk for developing depression as compared to the offspring of parents without a history

\footnotetext{
* Corresponding author. College of Physicians and Surgeons, Columbia University, New York State Psychiatric Institute, Unit 24, 1051 Riverside Drive, New York, NY 10032, USA. Tel.: +1 212543 5880; fax: +1 2125683534 .

E-mail address: mmw3@columbia.edu (M. Weissman).
}

of this disorder (Weissman et al., 1987; Orvaschel et al., 1988; Puig-Antich et al., 1989). The depression faced by these offspring is impairing; yet few receive any treatment (Weissman et al., 1987). Despite the wealth of evidence demonstrating the increased risk of MDD in the children of depressed parents, the mechanisms behind this risk are not well understood, and early signs of MDD are unclear (Downey and Coyne, 1990; Goodman and Gotlib, 1999).

Temperament in offspring could serve as one early sign of risk for a psychiatric disorder. Temperamental characteristics are evident early in life and stable over time, irregularities in temperament have been shown to 
predict future psychiatric and behavioral problems, and there is evidence of a relationship between psychiatric disorder in parents and temperament in their children (Maziade et al., 1986; Mufson et al., 1990; Frick, 2004).

Difficult temperament and extreme temperamental traits have been linked to a wide range of psychological and behavioral problems in both adolescence and adulthood - including substance abuse, social phobia, generalized anxiety disorder, depressive symptoms and disorders, delinquency, aggression, and convictions for violent offenses (Kashani et al., 1991; Henry et al., 1996; Merikangas et al., 1999; Sanson and Prior, 1999; Giancola and Mezzich, 2003; Elovainio et al., 2004; Giancola, 2004). Some studies have found associations between specific characteristics of temperament and depression, as well as other mood disorders. Elovainio et al. (2004), for example, demonstrated that impulsiveness, shyness with strangers, fatigability, sentimentality, and persistence increased the risk for depressive symptoms among a sample of men and women aged 20 to 35, and Caspi et al. (1996) found that children who were inhibited - that is shy, fearful, easily upset by strangers, or had difficulty concentrating on tasks at age 3 were twice as likely as other temperament groups to develop a mood disorder by age 21 . In general, temperament traits associated with negative emotionality (e.g., irritability, neuroticism, tendency toward discomfort see Compas et al., 2004, for review) have been shown to correlate positively with depressive symptoms and disorders in adults, whereas those associated with positive emotionality (activity, approach-withdrawal, sociability) are negatively correlated with these symptoms (Enns and Cox, 1997; Klein et al., 2002). Poor attentional-control (ability to concentrate, task persistence) has also been linked with depression in the literature (Rothbart et al., 1995).

There is also evidence linking parental psychopathology with temperament in offspring. In a community sample of 210 children and adolescents, Kashani and colleagues (1991) found that children with a difficult temperament were more likely to have parents with a psychiatric disorder. Durbin et al. (2005) found that low Positive Emotionality (PE) in young children was related to mood disorders in their mothers, though this relationship did not hold for other categories of disorders, or for negative emotionality. Merikangas et al. (1998) found scores on the activity subscale of temperament to be highest among offspring of parents with substance use disorders, and lowest among offspring of parents with anxiety and/or affective disorders. Offspring of the anxiety/affective disorder group also demonstrated less regular sleeping and eating habits. Finally, employing a subset of offspring of the current study participants - those whose temperament was assessed at the initial recruitment and whose diagnoses were assessed 10 years later - Mufson et al. (2002) documented that offspring of parents with comorbid MDD and anxiety disorders had significantly lower levels of adaptability/approachability than those of parents with MDD alone. Children of parents with MDD also showed less regular eating and sleeping habits than children of parents without any history of psychiatric disorder.

Given the observed relationships between parental psychopathology and child temperament, and between temperament and disorders in children, it has been hypothesized that temperament may be a mechanism through which depression is passed from parent to child (Goodman and Gotlib, 1999; Costello et al., 2002). However, parental depression is independently a significant risk factor for disorders among offspring, and previous studies have not addressed how much additional impact measures of child temperament confer on the development of depressive disorders among children who are already exposed to the risk of parental depression. The current report employs a sample of offspring of parents with MDD ("high-risk") or without MDD ("low risk"), followed over a span of more than 20 years, to examine the relationships between parental MDD, offspring temperament and offspring MDD. We evaluated the hypothesis that difficult temperament, as measured using the Dimensions of Temperament Survey (DOTS; Lerner et al., 1982), mediates the relation between parental MDD and offspring MDD. To test this hypothesis, we addressed four questions: (1) Is parental MDD associated with difficult temperament? (2) Is parental MDD associated with offspring MDD; (3) Is difficult temperament associated with offspring MDD? (4) Is the relation between parental MDD and offspring MDD reduced with temperament in the model? As a secondary purpose, we also examined whether or not parental MDD and difficult temperament interact to determine risk of MDD in offspring.

\section{Methods}

\subsection{Subjects}

Offspring at high or low risk for depression by virtue of the presence or absence of major depression in their parents were followed into adulthood over a period of 20 years. Depressed parents were originally selected from patients seeking treatment at the Yale University Depression Research Unit. Depression in the parents as assessed 
by the Schedule for Affective Disorders and Schizophrenia-Lifetime Version (SADS-L; Mannuzza et al., 1986) was moderate to severe and resulted in significant psychosocial impairment. Control subjects were selected from a 1975 survey of the New Haven community (Weissman et al., 1987, 1997, 2006). They had no history of psychiatric illness as determined by at least four direct interviews, the later two using the SADS. All parents were Caucasian and group matched for age and sex. [See Weissman et al. (2006) for a full description of the study methods.] Assessments of offspring and parents were conducted at baseline (Wave 1), 2 years later (Wave 2), 10 years later (Wave 3 ) and about 20 years after baseline (Wave 4). Two hundred-twenty offspring received diagnostic assessments at Wave 1. The sample utilized in this study is the 169 offspring who had (1) a Wave 1 interview, (2) completed the Dimensions of Temperament Survey (DOTS; Lerner et al., 1982) at Wave 1 or 2, and (3) had a follow-up interview at either wave 3 or 4 (or both). At the time of the assessment of temperament, the mean age for the 169 offspring was 16.8 years (S.D. $=4.7$ ), and $54 \%$ were female. There were no significant differences between the 169 offspring who were included in this study and the 51 who were not in sex or age of offspring, or parental MDD status.

\subsection{Instruments}

\subsubsection{Diagnostic assessments}

Offspring and parents were interviewed up to 4 times (Waves 1,2,3, and 4) using a semi-structured diagnostic assessment; the Schedule for Affective Disorders and Schizophrenia-Lifetime Version (SADS-L) was used for adults (Mannuzza et al., 1986), and for participants aged 6 to 17 , the child version was utilized (K-SADS-E) (Kaufman et al., 1997; Orvaschel et al., 1982). For all subjects under the age of 18 , both the child and parent were interviewed about the child. All interviews were conducted by trained doctoral and masters level mental health professionals; interviewers were blind to the parents' diagnostic status and any previous diagnoses in the offspring. Diagnoses were based on the best estimate (BE) procedure (Leckman et al., 1982). A random sample of 187 cases across all generations was co-rated by the diagnosticians; the inter-rater reliability kappa score for the diagnosis of MDD was .82. Lifetime diagnosis of MDD in offspring refers to a diagnosis of MDD made at any of the four waves.

\subsubsection{Assessment of temperament}

Offspring completed the DOTS at the time of first or second interview. The instrument is designed to assess the dimensions of temperament associated with social maladjustment. The DOTS is comprised of 34 items, representing five factors or subscales: Activity Level (activity during sleep), attention span/distractibility (task persistence), adaptability/approach-withdrawal (response to novel situations), rhythmicity (regularity of eating and sleeping habits) and irritability (reactivity to sensory stimuli, intensity of reaction to stimuli, and restlessness). The survey is self administered. All questions require a "true" or "false" response. A total temperament score was computed by summing all of the subscale scores. Scoring was adjusted so that a higher score represents a more difficult temperament. The possible range of scores is 0 to 34 . The median total temperament score served as a cutoff for categorical analyses, with those scoring equal to or above the median (i.e., 13) designated as having a difficult temperament and those scoring below the median referred to as having an easy temperament (Thomas and Chess, 1977, 1981). If available, the Wave 1 report of temperament was used. If there was no report at Wave 1, Wave 2 report of temperament was used. Assessments of temperament were carried out in 155 offspring at Wave 1 and in 14 at Wave 2.

\subsection{Data analyses}

The statistical tests aimed at evaluation of difficult temperament as a mediator of the relation between parental MDD and offspring MDD. For these analyses, we examined the association of both parental MDD and difficult temperament with offspring lifetime MDD, MDD at time of temperament assessment, and new onsets of MDD for those offspring not depressed at or before the time of assessment of temperament. First, temperament subscale and total scores at baseline (Wave 1 or 2) were compared between offspring with or without parental MDD using an Analysis of Covariance (ANCOVA) that adjusted for the child's age. Second, the association of parental MDD with offspring MDD and difficult temperament treated as a categorical variable was evaluated using logistic regression that adjusted for age at most recent interview. Third, the association of offspring temperament treated as a categorical variable and offspring MDD was evaluated using logistic regression that adjusted for age at most recent interview. Fourth, a logistic regression analysis was used to address the question of when you add temperament into the model do you explain at least $10 \%$ of the association of parental MDD and offspring MDD, and does temperament remain significant? Fifth, to compare the effect of difficult temperament on MDD in offspring with or without parental 
Table 4

Association between parental MDD and offspring MDD

\begin{tabular}{|c|c|c|c|c|}
\hline & $\begin{array}{l}\text { Difficult temp } \\
(\mathrm{T} 1)^{\mathrm{a}}\end{array}$ & $\begin{array}{l}\text { Parental } \\
\text { MDD }\end{array}$ & $\begin{array}{l}\text { Parental MDD adjusted for offspring } \\
\text { temperament }\end{array}$ & \\
\hline & Beta (s.e.) ${ }^{\mathrm{b}}$ & $\operatorname{Beta}(s . e)^{b}$ & Beta (s.e.) ${ }^{\mathrm{b}}$ & $\%$ Change (beta) \\
\hline \multicolumn{5}{|l|}{ Outcome } \\
\hline Lifetime MDD & $0.86(0.34)^{*}$ & $1.4(0.36)^{* * *}$ & $1.3(0.37)^{* * *}$ & $7.2 \%$ \\
\hline $\begin{array}{l}\text { MDD before or at time of assessment } \\
\text { of temperament }\end{array}$ & $0.53(0.37)$ & $0.99(0.40)^{*}$ & $0.86(0.41)^{*}$ & $13.1 \%$ \\
\hline New onsets & $1.0(0.50)^{*}$ & $1.6(0.58)^{* *}$ & $1.4(0.59)^{*}$ & $12.5 \%$ \\
\hline
\end{tabular}

$* P<0.05$.

$* * P<0.01$

$* * * P<0.001$

a Temperament treated as a categorical variable, dichotomized around the median.

b Adjusted for offspring age.

Table 4 (under $\%$ change in beta), when temperament was added to the model, it explained 7.2 to $13.1 \%$ of the association between parental MDD and offspring MDD. Moreover, the relationship between temperament and lifetime MDD in offspring remained significant, except for MDD at the time of temperament assessment. We also examined whether these results were influenced by gender. There was no significant Gender by Parental MDD interaction or Gender by Temperament interaction when predicting lifetime MDD at time of temperament assessment or new onsets of MDD.

We also evaluated whether the impact of offspring temperament on offspring MDD was different for the high- and low-risk offspring (Table 5). Rates of MDD in the offspring were examined for each combination of offspring temperament (difficult vs. easy) and parental depression status ( $\geq$ one vs. no parent depressed). Among low-risk offspring with neither parent depressed, those who had a difficult temperament had significantly higher rate of lifetime MDD when compared to those with an easy temperament. A similar trend was also evident among high-risk offspring with one or more depressed parent, but the difference in MDD rates between the difficult and easy temperament groups did not achieve a conventional level of statistical significance $(P<0.05)$. There was, however, no statistically significant Parental MDD by Offspring Temperament interaction for predicting MDD rates in offspring.

\section{Discussion}

Offspring of parents with a MDD are at increased risk for developing a depressive disorder (Weissman et al., 1987; Orvaschel et al., 1988; Puig-Antich et al., 1989). Four findings of the present study support the conclusion that difficult temperament, as measured by the

Table 5

Rates of MDD in offspring by temperament and parental diagnosis $(n=169)$

\begin{tabular}{|c|c|c|c|c|c|c|c|}
\hline & \multicolumn{3}{|c|}{$\begin{array}{l}\text { Low risk offspring (neither parent depressed) } \\
n=56\end{array}$} & \multicolumn{3}{|c|}{$\begin{array}{l}\text { High-risk offspring ( } \geq 1 \text { parent depressed) } \\
n=113\end{array}$} & \multirow[t]{2}{*}{$\begin{array}{l}\text { Parental MDD by offspring } \\
\text { T1 Temp interaction }\end{array}$} \\
\hline & $\begin{array}{l}\text { Easy } \\
\text { temperament } \\
(n=32) \\
N(\%)\end{array}$ & $\begin{array}{l}\begin{array}{l}\text { Difficult } \\
\text { temperament } \\
(n=24) \\
N(\%)\end{array} \\
N(\%)\end{array}$ & $\begin{array}{l}\text { Adjusted } \mathrm{OR}^{\mathrm{a}} \\
{[95 \% \mathrm{CI}]}\end{array}$ & $\begin{array}{l}\text { Easy } \\
\text { temperament } \\
(n=41) \\
n(\%)\end{array}$ & $\begin{array}{l}\text { Difficult } \\
\text { temperament } \\
(n=72) \\
n(\%)\end{array}$ & $\begin{array}{l}\text { Adjusted OR }{ }^{\mathrm{a}} \\
{[95 \% \mathrm{CI}]}\end{array}$ & \\
\hline Lifetime MDD & $6(18.7 \%)$ & $9(37.5 \%)$ & $4.6(1.1,19.2)^{*}$ & $19(46.3 \%)$ & $47(65.3 \%)$ & $2.2(0.96,4.7)^{+}$ & NS \\
\hline $\begin{array}{c}\text { MDD at time of } \\
\text { assessment of } \\
\text { temperament }\end{array}$ & $5(15.6)$ & $6(25.0)$ & $3.9(0.79,20.1)^{+}$ & 13(31.7) & $30(41.7)$ & $1.5(0.63,3.4)$ & NS \\
\hline New onsets & $1(3.7)$ & $3(16.7)$ & $4.9(.44,55.3)$ & $6(21.4)$ & $17(40.4)$ & $2.5(.85,7.6)+$ & NS \\
\hline
\end{tabular}

$* P<0.05$.

$+P<0.1$.

$\mathrm{OR}=$ Odds ratio.

NS $=$ Not significant at $P<0.05$.

a Adjusted for age. 
DOTS (Lerner et al., 1982), partially mediates the relation between parental depression and childhood depression. First, in this subsample of offspring from our longitudinal, high-risk study (Weissman et al., 1987), those with one or more depressed parent had more than a three-fold increased risk of developing a MDD when compared to those with neither parent depressed. Second, parental MDD was associated with difficult temperament in offspring. High-risk offspring were significantly more likely than low-risk offspring to have a difficult temperament, which is in accord with prior reports that difficult temperament is more likely to be seen in children having parents with psychiatric disorders (Kashani et al., 1991; Mufson et al., 2002). Third, difficult temperament was associated with increased rates of MDD, which agrees with the findings of other studies of temperament and depression (Rothbart et al., 1995; Caspi et al., 1996; Merikangas et al., 1998; Windle and Davies, 1999). Offspring with a difficult temperament were two to three times as likely as those with an easy temperament to have a MDD. This was true not only at the time when temperament was assessed (Wave 1 or 2), and but also for new onsets of MDD that developed after these assessments. Fourth, temperament explained 7.2 to $13.1 \%$ of the association between parental depression and offspring depression.

The results indicate that difficult temperament is associated with the development of depression in both high- and low-risk offspring. In the high-risk group, although depression was still common among offspring with easy temperaments, offspring with a difficult temperament were twice as likely as those with an easy temperament to develop depression. In the low risk group, offspring with a difficult temperament were more than four times as likely as those without to have a MDD. This observation is similar to that of previous studies comparing offspring at high- and low-risk for depression that have found family discord factors to be more strongly associated with offspring psychopathology (particularly, depressive, anxiety and substance use disorders) in the low-risk individuals (Fendrich et al., 1990, Nomura et al., 2002). Even though a formal test of interaction failed to find a significant difference between the high and low risk individuals in the odds of having MDD given a difficult temperament, the greater impact in low-risk individuals may represent a masking effect by the overwhelming impact of parental psychopathology in the high-risk group, and suggests that the direct impact of measures such as temperament may be more clearly assessable in the absence of parental depression.

Limitations of this study should be acknowledged. Because many of the offspring did not enter the study as young children, about $30 \%$ had experienced a major depressive episode prior to their initial interview. When only offspring with onsets of depression after assessments of temperament were included, offspring with a difficult temperament were three-times as likely as offspring with an easy temperament to have a MDD. Irrespective, we can not conclude that temperament plays a causal role in the development of a depressive disorder among offspring with no history of depression. A second limitation is the relatively small sample sizes, in particular for predicting new onsets of MDD in the years after temperament assessment. The findings for new onsets of MDD were, however, in general agreement with those seen for lifetime MDD.

In conclusion, parental MDD is a well-known risk factor for offspring depression. Our findings indicate that difficult temperament in offspring is related to increased rates of major depression and suggest that difficult temperament at least partially mediates the relation between parental MDD and offspring MDD. Given the substantial risk of depression in the offspring with both a difficult temperament and a parent with depression, this group deserves early identification.

\section{Acknowledgments}

The authors express their gratitude to Min Tang, M.S. for assistance with statistical analyses. This study was supported by NIMH grant R01MH036197 (P.I., Myrna M. Weissman).

\section{References}

Caspi, A., Moffit, T.E., Newman, D.L., Silva, P.A., 1996. Behavioral observations at age 3 years predict adult psychiatric disorders. Archives of General Psychiatry 53, 1033-1039.

Compas, B.E., Connor-Smith, J., Jaser, S.S., 2004. Temperament, stress reactivity, and coping: implications for depression in childhood and adolescence. Journal of Child and Adolescent Clinical Psychology 33, 21-31.

Costello, E.J., Pine, D.S., Hammen, C., March, J.S., Plotsky, P.M., Weissman, M.M., 2002. Development and natural history of mood disorders. Biological Psychiatry 128, 529-542.

Downey, G., Coyne, J.C., 1990. Children of depressed parents: an integrative review. Psychological Bulletin 108, 50-76.

Durbin, C.E., Klein, D.N., Hayden, E.P., Buckley, M.E., Moerk, K.C., 2005. Temperamental emotionality in preschoolers and parental mood disorders. Journal of Abnormal Psychology 114, 28-37.

Elovainio, M., Kivimaki, M., Puttonen, S., Heponiemi, T., Pulkki, L., Keltikangas-Jarvinem, L., 2004. Temperament and depressive symptoms: A population-based longitudinal study on Cloninger's psychobiological temperament model. Journal of Affective Disorders 83, 227-232.

Enns, M.W., Cox, B.J., 1997. Personality dimensions and depression: review and commentary. Canadian Journal of Psychiatry 42, 274-284. 
Fendrich, M., Weissman, M.M., Warner, V., 1990. Screening for depressive disorder in children and adolescents: validating the Center for Epidemiologic Studies Depression Scale for Children. American Journal of Epidemiology 131 (3), 538-551.

Frick, P.J., 2004. Integrating research on temperament and childhood psychopathology: its pitfalls and promise. Journal of Clinical Child and Adolescent Psychology 33, 2-7.

Giancola, P.R., 2004. Difficult temperament, acute alcohol intoxication, and aggressive behavior. Drug and Alcohol Dependence 74, $135-145$.

Giancola, P.R., Mezzich, C., 2003. Executive functioning, temperament, and drug use involvement in adolescent females with a substance use disorder. Journal of Child Psychology and Psychiatry 44, 857-866.

Goodman, S.H., Gotlib, I.H., 1999. Risk for psychopathology in the children of depressed mothers: a developmental model for understanding mechanisms of transmission. Psychological Review 106, 458-490.

Henry, B., Caspi, A., Moffitt, T., Silva, P., 1996. Temperamental and familial predictors of violent and nonviolent criminal convictions: age 3-18. Developmental Psychology 32, 614-623.

Kashani, J.H., Ezpeleta, L., Dandoy, A.C., Doi, S., Reid, J.C., 1991. Psychiatric disorders in children and adolescents: the contribution of the child's temperament and the parents' psychopathology and attitudes. Canadian Journal of Psychiatry 39, 569-573.

Kaufman, J., Birmaher, B., Brent, D., Rao, U., Flynn, C., Moreci, P., Williamson, D., Ryan, N., 1997. The Schedule for Affective Disorders and Schizophrenia for School Aged Children: Present and Lifetime Version (KSADS-PL): initial reliability and validity data. Journal of the American Academy of Child and Adolescent Psychology 36, 980-988.

Klein, D.N., Durbin, C.E., Shankman, S.A., Santiago, N.J., 2002. Depression and personality. In: Gotlib, I.H., Hammen, C.L. (Eds.), Handbood of Depression and its Treatment. Guildford, New York, pp. $115-140$.

Leckman, J.F., Sholomskas, D., Thompson, D., Belanger, A., Weissman, M.M., 1982. Best estimate of lifetime psychiatric diagnosis: a methodological study. Archives of General Psychiatry 39, 879-883.

Lerner, R.M., Palermo, M., Spiro III, A., Nesselroade, J.R., 1982. Assessing the dimensions of temperamental individuality across the life span: the Dimensions of Temperamental Survey (DOTS). Child Development 53, 149-159.

Mannuzza, S., Fyer, A.J., Klein, D.F., Endicott, J., 1986. Schedule of Affective Disorder and Schizophrenia-Lifetime version modification for the study of anxiety disorders (SADS-LA): rationale and conceptual development. Journal of Psychiatry Research 20, 317-325.

Maziade, M., Cote, R., Boudreault, M., Thiverge, J., Boutin, P., 1986. Family correlates of temperament continuity and change across middle childhood. American Journal of Orthopsychiatry 56, 195-203.

Merikangas, K.R., Swendsen, J.D., Preisig, M.A., Chazan, R.Z., 1998. Psychopathology and temperament in parents and offspring: results of a family study. Journal of Affective Disorders 51, 63-74.
Merikangas, K.R., Avenevoli, S., Dierker, L., Grillon, C., 1999. Vulnerability factors among children at risk for anxiety disorders. Biological Psychiatry 46, 1523-1535.

Mufson, L., Fendrich, M., Warner, V., 1990. The stability of temperament by child and mother reports over two years. Journal of the American Academy of Child and Adolescent Psychiatry 29, 386-392.

Mufson, L., Nomura, Y., Warner, V., 2002. The relationship between parental diagnosis, offspring temperament and offspring psychopathology: a longitudinal analysis. Journal of Affective Disorders 71, 61-69.

Nomura, N., Wickramaratne, P.J., Warner, V., Mufson, L., Weissman, M.M., 2002. Family discord, parental depression, and psychopathology in offspring: ten-year follow-up. Journal of the American Academy of Child and Adolescent Psychiatry 41, 402-409.

Orvaschel, H., Puig-Antich, J., Chambers, W., Tabrizi, M.A., Johnson, R., 1982. Retrospective assessments of prepubertal major depression with Kiddie-SADS-E. Journal of the American Academy of Child and Adolescent Psychiatry 21, 392-397.

Orvaschel, H., Walsh-Allis, G., Ye, W.J., 1988. Psychopathology in children of parents with recurrent depression. Journal of Abnormal Child Psychology 16, 17-28.

Puig-Antich, J., Goetz, D., Davies, M., Kaplan, T., Davies, S., Ostrow, L., Asnis, L., Twomey, J., Iyengar, S., Ryan, N., 1989. A controlled family history study of prepubertal major depressive disorder. Archives of General Psychiatry 46, 406-418.

Rothbart, M.K., Posner, M.I., Hershey, K.L., 1995. Temperament, attention, and developmental psychopathology. In: Cicchetti, D., Cohen, D. (Eds.), Developmental Psychopathology. Theory and Methods, vol. 1. Wiley, New York, pp. 315-340.

Sanson, A., Prior, A., 1999. Temperament and behavioral precursors to oppositional defiant disorder and conduct disorder. In: Quay, H., Hogan, A. (Eds.), Handbook of Disruptive Behavior Disorders. Kluwer, Dordrecht, Netherlands, pp. 397-417.

Thomas, A., Chess, S., 1977. Temperament and Development. Brunner/Mazel, New York.

Thomas, A., Chess, S., 1981. The role of temperament in the contributions of individuals to their development. In: Lerner, R.M., Busch-Rossnagel, N.A. (Eds.), Individuals as Producers of their Development: a Life-Span Perspective. Academic Press, New York.

Weissman, M.M., Gammon, G.D., John, K., Merikangas, K.R., Warner, V., Prusoff, B.A., Sholomskas, D., 1987. Children of depressed parents: increased psychopathology and early onset of major depression. Archives of General Psychiatry 44, 847-853.

Weissman, M.M., Warner, V., Wickramaratne, P., Moreau, D., Olfson, M., 1997. Offspring of depressed parents 10 years later. Archives of General Psychiatry 54, 932-940.

Weissman, M.M., Wickramaratne, P., Nomura, Y., Warner, V., Pilowsky, D., Verdeli, H., 2006. Offspring of depressed parents: 20 years later. American Journal of Psychiatry 163, 1001-1008.

Windle, M., Davies, P.T., 1999. Depression and heavy alcohol use among adolescents: concurrent and prospective relations. Development and Psychopathology 11, 823-844. 